Epidemiology and Psychiatric

Sciences

cambridge.org/eps

\section{Editorials in This Issue}

Cite this article: Oram S (2019). Sexual violence and mental health. Epidemiology and Psychiatric Sciences 28, 592-593. https:// doi.org/10.1017/S2045796019000106

Received: 4 February 2019

Accepted: 18 February 2019

First published online: 12 April 2019

\section{Key words:}

Health service research; mental health; psychiatric services; sexual assault; trauma

Author for correspondence: Sian Oram, E-mail: sian.oram@kcl.ac.uk

\section{Sexual violence and mental health}

\section{Sian Oram}

Section of Women's Mental Health, Institute of Psychiatry, Psychology and Neuroscience, King's College London, UK

The scale of sexual violence is staggering. It includes, but is not limited to, rape within marriage or dating relationships; rape by strangers or acquaintances; unwanted sexual advances or sexual harassment, including at work and at school; systematic rape, sexual slavery and other forms of violence, which are particularly common in armed conflicts; the sexual abuse of people with physical and mental disabilities; the sexual abuse of children; and 'customary' forms of sexual violence such as forced marriage or cohabitation and wife inheritance (World Health Organisation, 2012). In the USA, the National Intimate Partner and Sexual Violence Survey reported that $19.3 \%$ of women participants - equating to 23 million women nationally had been raped in their lifetime (Breiding, 2015). In Europe, the European Union's Fundamental Rights Survey found that 5\% (9 million) women had been raped since the age of 15 (with prevalence varying from 4 to $17 \%$ between participating states) and that $0.8 \%$ (1.5 million) had been raped in the last 12 months (European Union Agency for Fundamental Rights, 2014).

Research suggests an association between sexual violence and a range of mental-health problems - including post-traumatic stress disorder, depression, psychosis and substance abuse problems - and also demonstrates that a high proportion of people in contact with mentalhealth services have experienced sexual violence (Oram et al., 2017). Survey research conducted in the UK by Khalifeh et al., for example, found that $40 \%$ female patients in contact with secondary mental-health services had experienced rape or attempted rape as adults, and that $10 \%$ had experienced sexual violence in the past 12 months alone (Khalifeh et al., 2015). More than half of those who had experienced rape or attempted rape reported having attempted suicide as a result of their experiences. In this issue of Epidemiology and Psychiatric Sciences, two editorials provide a comprehensive discussion of the response of mental-health services to sexual violence, finding it to be, too often, lacking or even actively harmful.

Drawing mostly on evidence from the UK and Australia, Hughes et al. report that many mental-health professionals do not routinely enquire about sexual violence (Hughes et al., 2019). Some do not understand the relevance of sexual violence to the development, maintenance and exacerbation of mental-health problems. Others fear causing distress by asking about sexual violence or feel ill-equipped to respond to a disclosure, including because of a lack of time, training and resources. Similar concerns have been raised in relation to enquiry about domestic violence in mental-health settings. Damningly, findings from the UK suggest little improvement in rates of enquiry in the decade since routine enquiry about sexual abuse was introduced into mental-health services.

Hughes et al. argue that it is not enough to improve the identification of sexual violence through increased enquiry: ensuring that any disclosure of sexual violence is appropriately received and responded to is vital. Evidence from qualitative research in Australia has highlighted that mental-health service users may not be believed upon disclosing sexual violence, and that support to access criminal justice and specialist support services is often lacking. Hughes et al. close by highlighting the important role of Sexual Assault Referral Centres, specialist facilities where people can receive immediate help and support for sexual violence, including access to a forensic medical examination, support from a crisis worker, and help to speak to the police. Research from Australia, Canada, the Netherlands and the UK suggests that up to $40 \%$ of people attending Sexual Assault Referral Centres are known to mental-health services, though little is known about pathways between the two. The recently launched MIMOSA study will follow-up people attending Sexual Assault Referral Centres in the UK to improve understanding of mental health and substance use needs and subsequent use of services.

In the second editorial, Sweeney et al. explore how mental-health service responses to sexual violence impact on survivors, setting out a vision for an improved approach to care (Sweeney et al., 2019). They report that there is little well-funded support is available for survivors of sexual violence, and that the response of mental-health services can be actively harmful. Failure to ask and to believe mental-health service users about experiences of sexual violence allows continued exposure to violence and abuse, risks psychological harm and jeopardises criminal proceedings. Too many survivors of sexual violence are exposed to practices within mental-health services that replicate experiences of coercion and force, including the 
use of restraint, seclusion and forcible injections (Agenda, 2018). And, as also highlighted by Hughes et al., too many experience sexual violence within mental-health services themselves (Care Quality Commission, 2018). Sweeney et al. call for an end to the silence that surrounds sexual violence and its effects, for services to embed trauma-informed approaches to care, and for greater recognition - and resourcing - of community-based services that provide specialist and in some cases peer-led support to survivors of sexual violence.

Several factors are likely to contribute to the lack of progress in improving mental-health service responses to sexual violence. Among them is the relatively low priority afforded to sexual violence by researchers and by research funders and publishers. Evidence is limited, for example, on the effectiveness of interventions to improve mental-health outcomes among survivors of sexual violence and to improve community, institutional and societal responses (Bisson and Andrew, 2007; Vickerman and Margolin, 2009). Sexual and other forms of violence are rarely measured or identified in trials of mental-health interventions, even though they are likely to be important moderators of response, and too limited consideration is given to common forms of violence against women in major survey and cohort studies (Oram et al., 2017). Epidemiology and Psychiatric Science's decision to commission these two editorials is a welcome one. Other recent developments may perhaps also give cause for optimism. In the UK, for example, the cross-disciplinary mental-health networks funded by UK Research and Innovation include a network on violence, abuse, and mental health (www.vamhn.co.uk), with a focus on domestic and sexual violence.

As Sweeney et al. highlight, research led and co-produced by survivors of sexual violence is needed in order to understand whether and how mental-health services are meeting the needs of survivors and to explore the potential of trauma-informed approaches in transforming care. While underlining the importance of survivor involvement in and leadership of research, they also highlight that participation can be difficult for many people and the need to take seriously the safety and emotional support needs of those involved. As described by Sweeney et al., the recently launched Charter for Organisations for Engaging Survivors in Projects, Research and Service Development sets out principles for safe, meaningful and effective involvement of survivors in research (Perot et al., 2018).

Survivors have been let down by too many and for too long. With the greater prioritisation of sexual violence in mental-health policy, services and research, this could finally change.

Author ORCIDs. (D) Sian Oram, 0000-0001-8704-0379.
Acknowledgements. Sian Oram receives grant funding from NIHR and UKRI. The views expressed are those of the author and not necessarily those of UK Research and Innovation, the NHS, the National Institute for Health Research, the Department of Health and Social Care or its arm's length bodies, or other Government Departments.

Financial support. None.

Conflict of interest. Sian Oram jointly leads the Violence Abuse and Mental Health Network.

\section{References}

Agenda (2018) Women in Crisis: How Women and Girls are Being Failed by the Mental Health Act. London: Agenda.

Bisson J and Andrew M (2007) Psychological treatment of post-traumatic stress disorder (PTSD). Cochrane Database of Systematic Reviews 18(3), CD003388.

Breiding MJ (2015) Prevalence and characteristics of sexual violence, stalking, and intimate partner violence victimization-national intimate partner and sexual violence survey, United States, 2011. American Journal of Public Health 105, E11.

Care Quality Commission (2018) Sexual Safety on Mental Health Wards. Newcastle: Care Quality Commission.

European Union Agency for Fundamental Rights (2014) Violence Against Women: An EU-Wide Survey. Vienna: FRA.

Hughes E, Lucock M and Brooker C (2019) Sexual violence and mental health services: a call to action. Epidemiology and Psychiatric Sciences https://dx.doi.org/10.1017/S2045796019000040

Khalifeh H, Moran P, Borschmann R, Dean K, Hart C, Hogg J, Osborn D, Johnson S and Howard L (2015) Domestic and sexual violence against patients with severe mental illness. Psychological Medicine 45, 875-886.

Oram S, Khalifeh H and Howard LM (2017) Violence against women and mental health. The Lancet Psychiatry 4, 159-170.

Perot C and Chevous J and Survivors' Voices Research Group (2018) Turning Pain into Power: A Charter for Organisations Engaging Abuse Survivors in Projects, Research \& Service Development. London: Survivors' Voices.

Sweeney A, Perot C, Callard F, Adenden V, Mantovani N and Goldsmith L (2019) Out of the silence: towards grassroots and trauma-informed support for people who have experienced sexual violence and abuse. Epidemiology and Psychiatric Sciences https://doi.org/10.1017/S2045796019000131

Vickerman KA and Margolin G (2009) Rape treatment outcome research: Empirical findings and state of the literature. Clinical Psychology Review 29, 431-448.

World Health Organisation (2012) Understanding and addressing violence against women: sexual violence. Available at https://apps.who.int/iris/ bitstream/handle/10665/77434/WHO_RHR_12.37_eng.pdf;jsessionid= 634A4D4179437008F6AFB01444D2A105? sequence=1 (Accessed 04/02/19), Geneva. 